\section{Notes and activities}

BSG and BSDE Spring Meeting, Coventry The Spring meetings of the British Society of Gastroenterology and the British Society of Digestive Endoscopy took place at the University of Warwick, Coventry, on 31 March-1 April. The meeting was ably organised by the local Secretaries Dr J. Howel Jones and Dr Bernard Smits. The Society of Digestive Endoscopy held a session of scientific communications and a symposium on the investigation of the jaundiced patient, chaired by the BSDE President, Dr Michael Atkinson. The BSG ran nine scientific sessions. One-hundred-and-eight papers were read before the two societies. The plenary session, chaired by the President, Dr W. Sircus, included the lecture entitled 'Peptide transport in the human small intestine' by this year's BSG Research Medallist, Dr D. B. A. Silk. Additional seminars were organised by the pathologists' and the radiologists' groups. The social programme included a performance of Midsummer Night's Dream at the Royal Shakespeare Theatre and a medieval banquet at Warwick Castle.

\section{Z-E Syndrome Register}

Clinicians are reminded that the register of patients suffering from the Z-E syndrome has been started. Completeness and success depends on your co-operation. Forms obtainable from Dr.W. L. Burland, Smith Kline and French Laboratories Ltd, Welwyn Garden City, Herts.

\section{University of Edinburgh-Edinburgh Surgical Festival}

The Festival, a forum for discussion of topics of current surgical interest with viewpoints presented by leading surgeons, will be held in Edinburgh from 6-8 September 1978. The programme concentrates on the gastrointestinal tract, shock and metabolism, surgical techniques, blood and blood vessels, and cancer. Organisers: Professor A. P. M. Forrest and Mr D. C. Carter. Fee: $£ 75$. Apply to Mrs J. M. Wake, Executive Secretary, Department of Clinical Surgery, Royal Infirmary, Edinburgh EH3 9YW. (Telephone: 031-229 2477, ext. 2161.)

\section{Applied Gastroenterology}

A symposium will be held at the London Hospital on 5 and 6 October 1978. The meeting will be divided into the following sessions (chairmen in parentheses): Small bowel function: current concepts (Professor H. D. Ritchie); Cholelithiasis: medical v. surgical management (Sir Rodney Smith); Ulcer disease (1) hypergastrinaemia (Mr J. B. Elder); Ulcer disease (2) medical v. surgical management of chronic duodenal ulcer (Professor M. Hobsley); Recent advances in paediatric gastroenterology (Dr G. Snodgrass); Inflammatory bowel disease: medical v. surgical management (Mr H. E. Lockhart-Mummery). Details can be obtained from The Secretary, Department of Surgical Studies, The London Hospital, Whitechapel, London, E1 1BB.

American Pancreatic Association, Inc. and National Pancreatic Cancer Project

The annual joint scientific meeting of these two organisations will be held on 2 and 3 November 1978, in Chicago, Illinois. Details may be obtained from Dr F. P. Brooks, American Pancreatic Association, Inc., Box 652, Hospital of the University of Pennsylvania, Philadelphia, Pa., 19104, or Dr Isidore Cohn, National Pancreatic Cancer Project, Louisiana State University Medical Center, 1542 Tulane Ave., New Orleans, LA 70112, USA.

\section{Books}

Alcohol and the Liver Edited by M. M. Fisher and J. G. Rankin. (Pp. 405; illustrated; $\$ 47.40$.) Plenum Press: New York, London. 1977.

Alcohol abuse is rapidly becoming one of the most compelling medicosocial problems of our time. The last decade or two has seen considerable advances in our understanding of the metabolic and toxic effects of alcohol-most notably on the human liver. In May 1976 the Canadian Hepatic Foundation brought together 'the committed experts of various disciplines for an updating of our understanding of alcohol and the liver and for a discussion of new approaches to the problem'. This book is born out of the Toronto meeting and fortunately its editors can be congratulated on making this more than just another of those dreary symposium proceedings we get pushed at us these days. Usually they contain little new information, are poorly written and edited, and are unexciting to look at. This book is an exception in that it is, on the whole, readable and authoritative and contains some unpublished work.
Hans Popper in his customarily masterful summing-up highlights the 'problems' in the field: the mechanisms of hepatocyte necrosis; the pathogenesis of chronicity; symptomatic management; prevention; and carcinogenesis and alcohol.

To some extent the contributions spell out what we know of these problems so far. As with all multi-author books the quality is sometimes variable but is on the whole excellent. The chapters by Schmidt on epidemiology, by Lundquist on metabolism, by Rubin and Cederbaum on micropathology, by Lieber and by Popper on pathogenesis, and by Isselbacher and by Feller and Rankin on natural history are especially noteworthy.

This book will repay a dip or two into it by most doctors (after all alcohol and one's liver is an unfailing topic of conversation in most circles). For hepatologists it will prove well worth reading and for those interested in the alcohol field it is a must.

P. W. BRUNT

Current Topics in Immunology Series Edited by J. L. Turk. No. 8.

Immunology of Gastrointestinal and Liver Disease By Ralph Wright (Pp. 132; illustrated; $£ 4 \cdot 75$, paperback.) Edward Arnold: London.

This volume is the eighth of a series devoted to current topics in immunology edited by Professor John Turk. The aim of the series is 'to provide the busy clinician in a particular field of medicine with a short volume relevant to his practice written by a specialist'. Professor Wright's volume should be of value not only to gastroenterologists but to all clinicians and to laboratory workers in the field.

The book is divided into two parts; the first dealing with the gastrointestinal tract and the second with the liver. Each part begins with a chapter describing the normal immunological functions and the role of the gut and liver in the immune response. Subsequent chapters deal with the immunology of specific diseases, and each finishes with an excellent summary. The book is well illustrated with figures and tables of original data, much of which are from Professor Wright's own work. The chapters on liver disease, especially drug-induced liver disease, are particularly well written and present an excellent perspective of this rapidly developing field. 